\title{
Landslide Hazard Zonation Map of Joshimath- Badrinath Region, India: Using Remote Sensing and GIS Technique
}

\footnotetext{
${ }^{1}$ Abhishek Maurya

${ }^{2}$ Shashikant Tripathi

${ }^{3}$ L. K. Sinha
}

\section{${ }^{1 \& 2}$ Remote Sensing and GIS Lab MGCGV Chitrakoot, India \\ ${ }^{3}$ DRDO, DTRL Lab New Delhi, India}

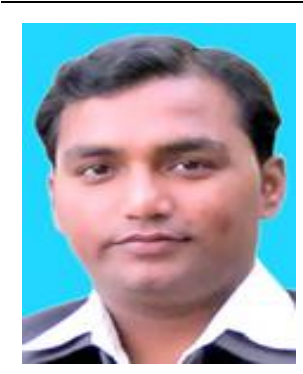

Corresponding author:

Abhishek Maurya avi.maurya@gmail.com

Received: February 24, 2017

Revised: June 29, 2017

Published: June 30, 2017

\begin{abstract}
During 15-17 of June 2013 triggered numerous landslides and caused widespread damage and loss of life in the study area. It affects most of the population and loss the life and wealth every year. Landslide Hazard is a common phenomenon in uttarakhand, India. It is an induced process either by torrential rain during monsoon or by seismic activity in the region. Remote Sensing and GIS technique is used to integrate geological and terrain factors and to prepare different thematic maps. IRS LISS-III MSS satellite imagery is used for classification processes and analysis. After overlaying all the thematic maps, landslide prone area and risk zone is demarcated. Joshimath- Badrinath region was chosen for the study. High risk of landslide in that area was $54 \%$ and While $25 \%$ area was at moderate risk and rest of the area was at low risk. The study is important for risk zone analysis prior to landslide to minimize the effect of hazard. So, this research is crucial for future purpose.
\end{abstract}

Keywords- Landslide, hazard zonation map, remote sensing, and GIS. 


\section{INTRODUCTION}

In this paper, we present a corroboration of observations gathered from high resolution satellite data which indicated that two events in close succession caused damage to the study area.During $15-17$ of June 2013 triggered numerous landslides and caused widespread damage and loss of life in the study area (Martha et al. 2015). The debris brought down by rivers from these landslides, particularly from the glaciated deposits in upstream areas, caused severe river bank erosion in downstream areas.

Landslide is rock, earth or debris flow on slope due to gravity. They can occur on any terrain given the right conditions of soil, moisture and the angle of slope. Integral to the natural process of the earth's surface geology, landslides serve to redistribute soil $\&$ sediment in a process that can be abrupt collapses or in slow gradual slides. It can be triggered by rains, floods, earthquakes, and other natural causes as well as human-made causes, such as grading, terrain cutting \& filling excessive development etc. because the factors affecting landslides can be geophysical or human made, they can occur in developed areas, or any area where terrain was altered for roads, houses, utilities, building. Landslides are like any other events such as floods, earthquakes and avalanche are natural phenomena. Which are often unpredictable and which have potentially detrimental consequences.

The principle factors that initiate or trigger mass movement are: (i) heavy and prolonged rainfall (ii) cutting and deep excavations on slope for construction of building, roads, canal and mining without appropriate disposal of debris, and (iii) earthquake shocks and tremors.

Landslides are complex natural phenomena that are hard to model and simulate. Predicting hazardous events like landslides are particularly difficult because no laboratory exists that can preliminarily measure important variables, refine the techniques, and apply the results (Dattilo and Spezzano, 2003). Mitigation of disasters on account of landslides can be successful only with detailed knowledge about the expected frequency, character and magnitude of mass movements in an area. For forecasting occurrence of landslides in near future in an area, comprehensive knowledge of causative factors of land sliding is necessary. Hence, the identification of landslide-prone regions is essential for carrying out quicker and safer mitigation programs, as well as future strategic planning for an area. Therefore, the Landslide Hazard Zonation (LHZ) of an area becomes significant whereby the area is classified into different LHZ ranging from very low hazard zone to very high hazard zone (Arora et. al., 2004). Landslide hazard and its mapping using remote sensing technique (Rai et al., 2014). Landslide hazard analysis focuses mainly on the spatial zoning of the hazard (Beek and Asch, 2004).

Landslides are natural events, but may turn into hazard and cause loss of lives and damage to man-made and natural structures. The term landslide hazard is defined by many authors differently, among them definition given by Burton et al. (1978), Rezig et al. (1996), Varnes and IAEG (1984), Cardinali et al. (2002), and Guzzetti (2003) are important.

Though there are numerous approaches to define landslide hazards, many of the researchers have largely adopted or modified the definition given by Varnes and IAEG (1984).

\section{Study Area}

It covers the following SOI toposheet: $53 \mathrm{~N} / 6,53 \mathrm{~N} / 10$. It extends from Longitude $=79^{\circ} 25^{\prime} \mathrm{E}$ to $79^{\circ} 40^{\prime} \mathrm{E}$ and Latitude $=30^{\circ} 30^{\prime} \mathrm{N}$ to $30^{\circ} 45^{\prime} \mathrm{N}$ (Fig. 1). The study 
area is located in the Lesser Himalayan segment of the Garhwal Himalaya. The rock types present in the area are quartzite, limestone, phyllite, chlorite schist and micaschist, are low to medium grade rocks that have suffered multiple phase of deformation. Badrinath has an average elevation of 3,100 metres (10,170 feet). It is in the Garhwal Himalayas, on the banks of the Alaknanda River. The town lies between the Nar and Narayana mountain ranges $9 \mathrm{~km}$ east of Nilkantha peak $(6,596 \mathrm{~m})$

\section{Data Used}

The present study is carried out with the help of following data:-

1. SOI toposheet- Following SOI toposheets were used: $-53 \mathrm{~N} / 6,53 \mathrm{~N} / 10$, (Scale 1:50,000)

2. Satellite data- LISS-III MSS data has been used and its characteristics given below in Table-1.

\section{METHODOLOGY}

As mentioned prior also two types of data were used in the present study. These were (I) Satellite Data, (II) Secondary Data. (Fig.2)

Secondary data includes SOI toposheets and geological maps and prior studies of the same area.

These data had been used to extract various themes. A total 7 themes was extracted as- landuse/landcover, drainage, transport, slope, aspect, lineament map and rose diagram. While one theme as lineament was extracted using both data. All those themes were assigned with weightage value to individual class in each theme in GIS environment using Arc-GIS 9.2. Overlay analysis was the next step, for overlay analysis union algorithm was used. There are many algorithms present in ArcGIS e.g. intersection etc. At a time only 2 themes were overlaid. Consequently LHZ map was prepared.

\section{Digital Elevation Model}

Digital Elevation Model shows the elevation of given area. With the help of digitized contours from SOI toposheet (1:50000) and DEM was created using Erdas 9.0. DEM was given colors indicating high, low, moderate relief. DEM was given no weightage and not used in overlay analysis directly. Study area has high relief on the southeastern and north part. Lowest elevation or no elevation was found in the river, zero values were given to these places. Elevation between 6,120 feet to 11,160 feet in the study area.

\section{Slope Map}

Slope is very important factor for landslide study. If the slope is higher then there is a chance of occurrence of landslide. Digital elevation model has been used for the preparation of slope map using ERDAS 9.0. Contours were digitized from the toposheet, and DEM was generated. Using the slope function in ERDAS, the slope map has been prepared. Slope is a very important parameter in any LHZ mapping. In the study area slope varies from 0 to greater than 85 degrees (Table-2 \& Fig. 3 ). The entire slope map was divided into categories and weights have been assigned to each category. Weightage value implement range was used $1-10.1$ is less weight and 10 is high weight for slope category. Rock fall or landslide mostly occur in 35-45 degree, so in this category weigthage is also high.

\section{Aspect Map}

Aspect plays a significant role in slope stability process. It is considered as important factor in landslides because, it divided the amount of sunlight which the slope receives higher amount of sunlight creates drier slopes with less vegetation and will be more prone to landslides 
compared to slopes with less sunlight. Slope aspect map was derived from the DEM. The aspect was divided into nine classes N, NE, E, SE, S, SW, W, NW and FLAT (Table-3).

\section{Drainage Map}

Drainage is an important factor, which reflects the slope evolution of area and an indicator of the mass wasting and related erosional aspects. Zones with the parallel pattern of drainage of drainage associated with strong slope control are the most probable situation for mass movement/landsides. Drainage is often a crucial measure due to the important role played by pore-water pressure in reducing shear strength. Because of its high stabilization efficiency in relation to cost, drainage of surface water and ground water is the most widely used and generally the most successful stabilization method. The drainage in the area is mainly dendritic consisting of a network of channels resembling tree branches.

In the study area drainage network is quantitative subjected to analysis. Drainage density computation has been done on $1 \mathrm{~km}$ grid (Soni et al 2013), based on length of drainage lines and integrated to form drainage density layer. Drainage density is defined as the total length of drainage per unit area and in the study area the drainage density values vary from 0 to $1 \mathrm{~km} / \mathrm{sq} . \mathrm{km}$. The drainage density values have been divided into three classes as low, medium, high and very high classes, and weights have been assigned for these classes.

\section{Land use / Land cover map:}

At first we should know what is image classification? "Image classification is the process of assigning pixels to classes." (Maurya et al. 2013 \& Soni et al. 2015). Land use change has been recognized throughout the world as one of the most important factors influencing the occurrence of rainfall-triggered landslides. land use/land cover categories of the study area were mapped using LISS-III MSS data. Supervised classification used for current mapping.The satellite data was visually interpreted and after making thorough field check, the map was finalized.

\section{Transport Map}

Landslide are viewed as a persistent problem along transportation corridors in mountains regions. Landslides not only cause damage to properties (alignment, building, vehicles, etc.) and life, but also affect the society by disrupting the utility services and economic activities (Fig.4).

\section{Structural map (Lineament/Thrust)}

A lineament is mappable simple or composite linear feature of a surface whose part is align in a linear or slightly curvilinear relationship and which differs distinctly from the pattern of the adjacent features and presumably reflects a surface phenomenon. Lineaments are the linear feature of geological importance. They show the local discontinuities in various rock types in the image. It displacement is clear then it is a fault is not clear then it is interpreted as lineament, LISS-III data was used as the source of the lineament mapping (Fig.5). There is one major thrust (North Almora thrust) passing through the area. The thrust has been digitized from the regional geological map of the area. The term lineament is used in a geomorphological sense as linear feature, which presumably reflects a sub-surface phenomenon. Generally the lineaments are related to the feature system, discontinuity planes, fault and sear zone in the rock. Mega fault (Alknanda Fault) is present in the north of the study area. The

lineament map has been buffered with distance of $250 \mathrm{~m}$. Thrust being more regional in feature has been buffered differentially. 


\section{Rose Diagram}

Rose diagrams explain the frequency of lineations in a given orientation. In structural geology rose diagrams are used to plot the orientation of joints and dykes. Rose diagram shows the total number of lineament in particular angle categories as like: 0-10 degree, 10-20 degree etc. Rose diagram also shows the length of lineament in particular angle categories as like: 0-10 degree etc. (Fig.6).

\section{RESULT \& DISCUSSION}

Landslide Hazard Zonation map was created using seven thematic layers extracted from satellite and secondary data. Themes taken here have direct or indirect effects on landslide. With the help of Remote Sensing \& GIS all these themes were identified, extracted and weights were assigned to each theme to overlay them in GIS environment. Some themes account less for landslide and some accounted more (Fig.7).

- Structural theme (fault, fold, thrust, and lineament) and topographical slope have very high influence on landslide.

- $54 \%$ area is landslide prone area i.e. high risk of landslide in that area.

- While $\mathbf{2 5 \%}$ area is at moderate risk and rest of the area is at low risk.

- Landuse/Landcover, transport themes are relatively less significant.

- Use of Remote Sensing \& GIS greatly helps to identify real dangerous areas (in respect to landslide) and give fairly good accuracy.

Since, the area is mountainous and has high dissected hills (in most places) probability of landslide is high and with the help of remote sensing and GIS, it is estimated.
Since population is increasing unceasingly, construction will keep increasing in high danger zones also. Moreover natural factor also contribute to it but we should try to mitigate man made causes. I am compiling this study with a prayer to god for less human life loss in landslides

\section{CONCLUSION}

Research methodology followed based on the scientific standardization and with the research principles. The definitions of the concepts was done step by step, as they were being implemented in research. The remote sensing and GIS tools were used for the analysis due to its capability of manipulation, implementation, storing and accuracy and less time consumptions.

This technology can be used as an effective aid in natural hazard investigation, as well as for the purpose of environmental planning. Landslide hazard zonation (LHZ) map was categorized three category as low, medium and high category. Drainage map, contour map, digital elevation model, slope angle map, land use / land cover map, relative relief map, lineament map, rose diagram map, are basic requirement for landslide hazard zonation or for identification of landslide prone areas which can be delineated under GIS environment using remote sensing data. Geographic Information System (GIS), as a computer- based system for data capture, input, manipulation, transformation, visualization, combination, query, analysis, modeling and output, with its excellent spatial data processing capacity, has attracted great attention in natural disaster assessment.54\% high risk of landslide in that area. So, with the help of this research, loss the life and wealth every year will be reduced.

\section{ACKNOWLEDGEMENT}


Authors are thankful to DTRL Lab, DRDO New Delhi, India for his encouragement and guidance has added new dimensions my knowledge. Thanks are also GIS lab of MGCGV University, India.

\section{REFERENCES}

Arora, M.K., Das Gupta, A.S.,Gupta, R.P., 2004. An artificial neural network approach for landslide hazard zonation in the Bhagirathi (Ganga) Valley, Himalayas. International Journal of Remote Sensing, 25(3): 559-572.

Beek, L.P.H.V.,Asch, T.W.JV., 2004. Regional assessment of the effects of land use change on landslide hazard by means of physically based modeling. Natural Hazards, 31: 289-304.

Burton, I., Kates, R., White, G., 1978. The environment as hazard. Oxford University Press, New York.

Cardinali, M., Reichenbach, P., Guzzetti, F., Ardizzone, F., et al., 2002. A geomorphological approach to estimation of landslide hazards and risks in Umbria, Central Italy. Nat Hazards Earth Syst Sci., 2:57-72.

Dattilo, G., Spezzano, G., 2003. Simulation of a cellular landslide model with CAMELOT on high performance computers. Parallel Computation, 29:1403-1418.

Guzzetti, F., 2003. Landslide Hazard Assessment and Risk Evaluation: Limits and Perspectives. Spain: University de les IllesBalears, Proceedings of the 4th EGS Plinius Conference held at Mallorca, Spain, pp. 1-4.

Martha T.R., Roy P., Govindharaj K.B., et al., 2015. Landslides triggered by the June 2013 extreme rainfall event in parts of Uttarakhand state, India, Landslide,12(1):135-146.
Maurya A.K., Tripathi S.K., and Soni S., 2013.Change Detection Mapping: Using Remote Sensing and GIS technology - A Case Study of Achanakmar-Amarkantak Biosphere Reserve, Central India.International Journal of Remote Sensing \& Geoscience, 2(3): 104-108.

Rai, P.K., Mohan, k., and Kumra, V.K., 2014. Landslide Hazard and Its Mapping Using Remote Sensing and GIS. Journal of Scientific Research, 58: 1-13.

Rezig, S., Favre, J., Leroi, E., 1996.The probabilistic evaluation of landslide risk. In: Sennset, editor. Landslides.Rotterdam: Balkema, pp. 351-355.

Soni S., Garg P.K., Singh A., and Maurya A.K., 2015.Assessment of land use land cover change in Chakrar watershed using geospatial technique. Tropical Forest Research, 2(2): 101-107.

Soni S., Tripathi S.K., and Maurya A.K., 2013. GIS based morphometric characterization of mini watershedRachhar Nala of anuppur district Madhya Pradesh.

Varnes D, IAEG. 1984. Landslide hazard zonation: a review of principles and practice. Paris: United Nations Scientific and Cultural $\mathrm{O}$ 
Table-1: shows the characteristics of satellite data

\begin{tabular}{|l|l|}
\hline System & LISS-III Characteristics \\
\hline Orbit & $\begin{array}{l}817 \mathrm{~km}, 98.80 \text { inclination, sun synchronous, } 24 \\
\text { day repeat cycle }\end{array}$ \\
\hline Swath & $140 \mathrm{~km}$ \\
\hline Spectral Band & $\begin{array}{l}\text { Band } 1-0.52 \text { to } 0.59 \\
\text { Band } 2-0.62 \text { to } 0.68 \\
\text { Band3 }-0.77 \text { to } 0.86 \\
\text { Band4 }-1.55 \text { to } 1.70\end{array}$ \\
\hline Spatial resolution & $23.5 \mathrm{~m}$ \\
\hline
\end{tabular}

Table-2: shows the Slope category and weightage. Table-3: the Aspect category and weightage.

\begin{tabular}{|c|c|}
\hline Slope( Degree) & Weightage \\
\hline $1-15$ & 1 \\
\hline $15-25$ & 2 \\
\hline $25-30$ & 6 \\
\hline $30-35$ & 7 \\
\hline $35-40$ & 9 \\
\hline $40-45$ & 9.5 \\
\hline $45-60$ & 8 \\
\hline$>60$ & 7.5 \\
\hline
\end{tabular}

\begin{tabular}{|c|c|}
\hline Aspect & Weightage \\
\hline North facing & 1 \\
\hline South facing & 10 \\
\hline NE facing & 3 \\
\hline NW facing & 2 \\
\hline SE facing & 6 \\
\hline SW facing & 4 \\
\hline East facing & 5 \\
\hline West facing & 2 \\
\hline Flat & 0 \\
\hline
\end{tabular}




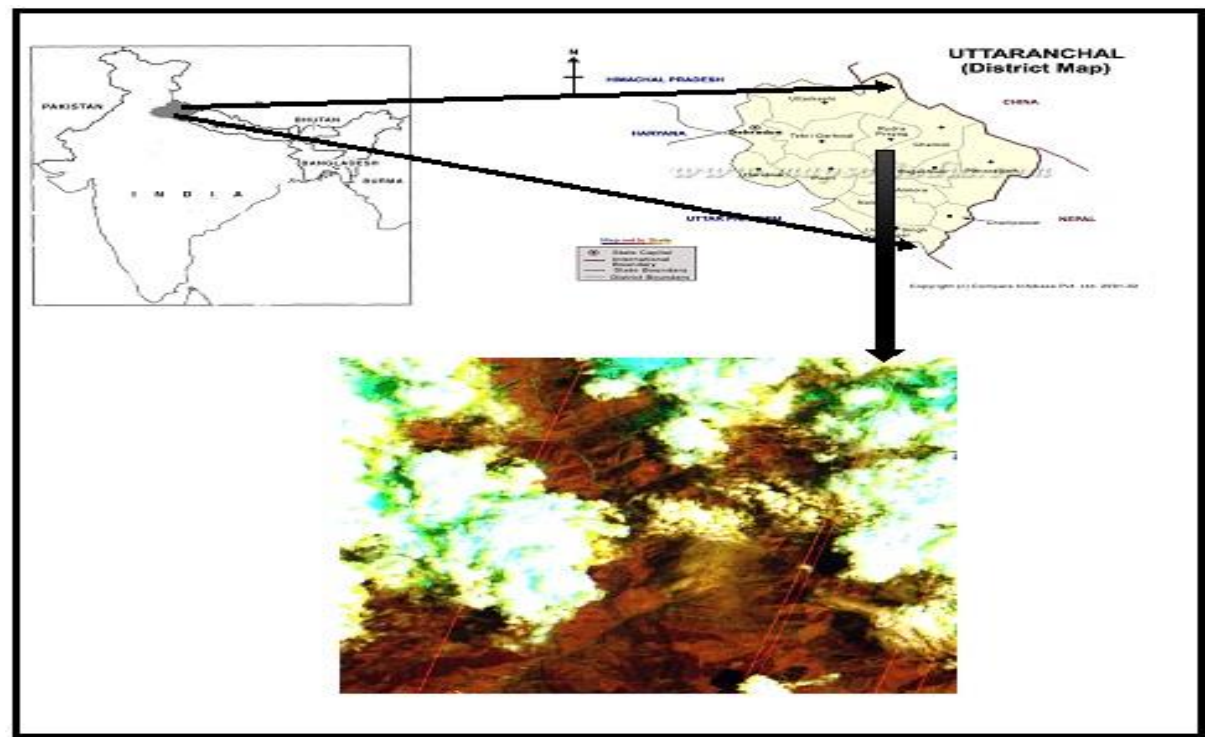

Figure-1: shows the location map of study area

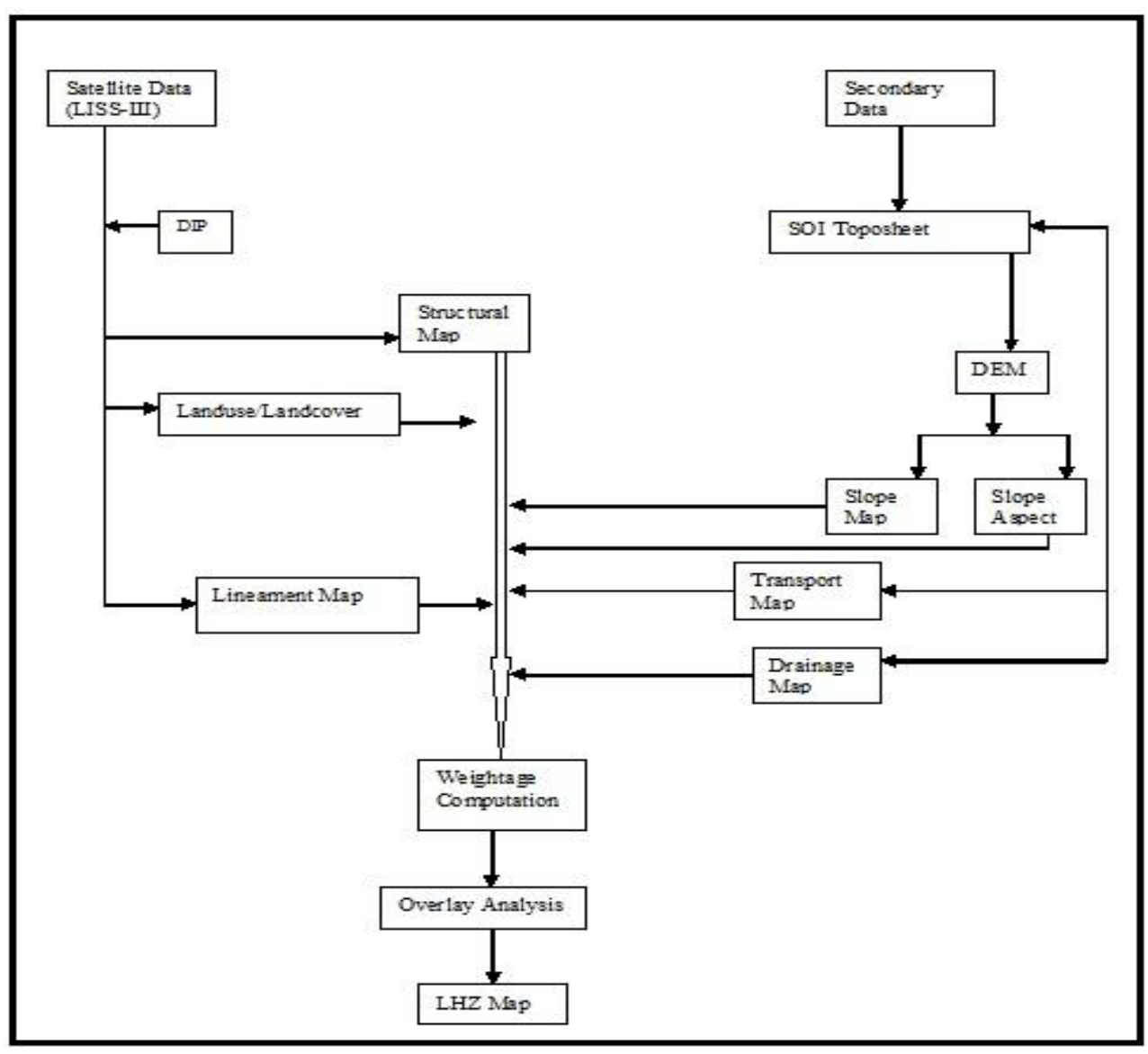

Figure-2: Shows the details methodology of LHZ mapping 


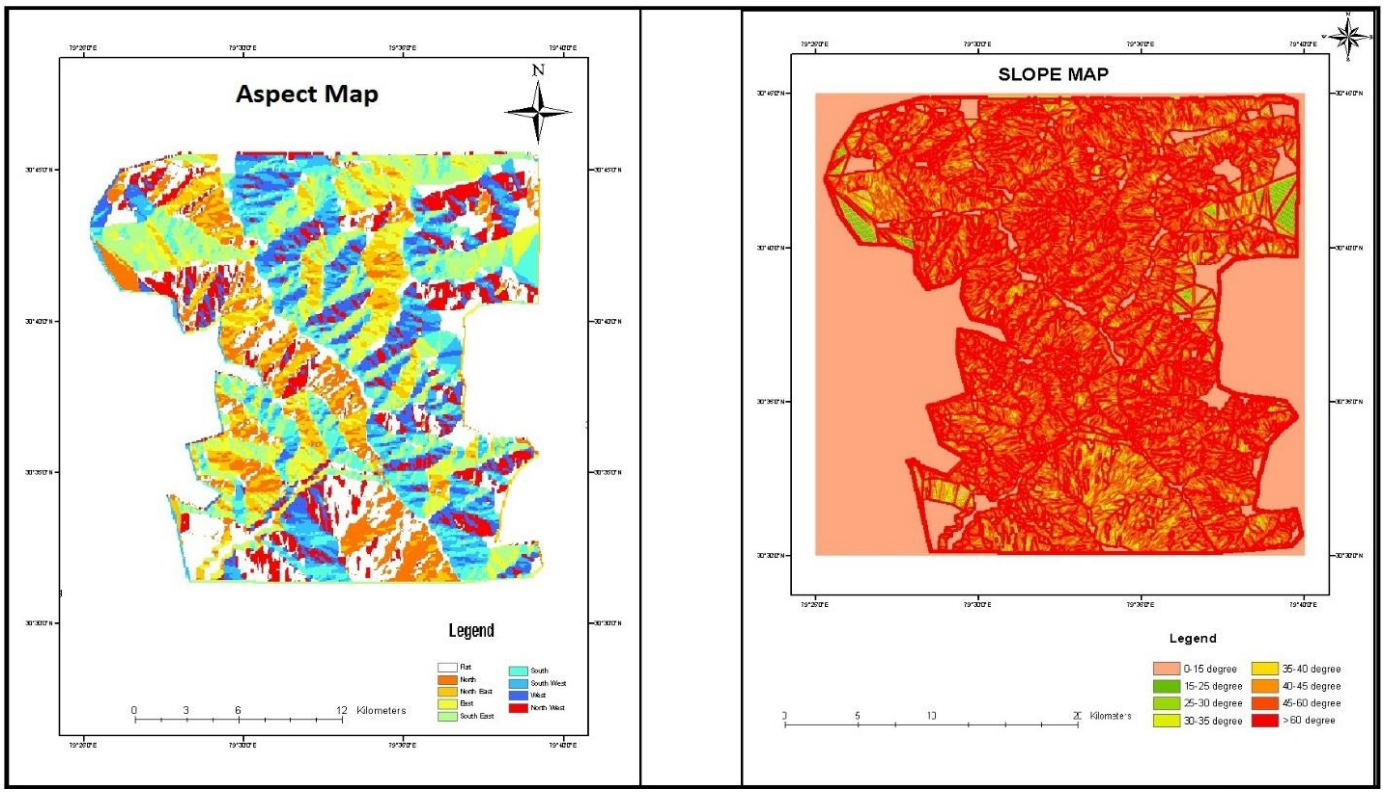

Figure-3: Shows the Slope \& Aspect Map of study area

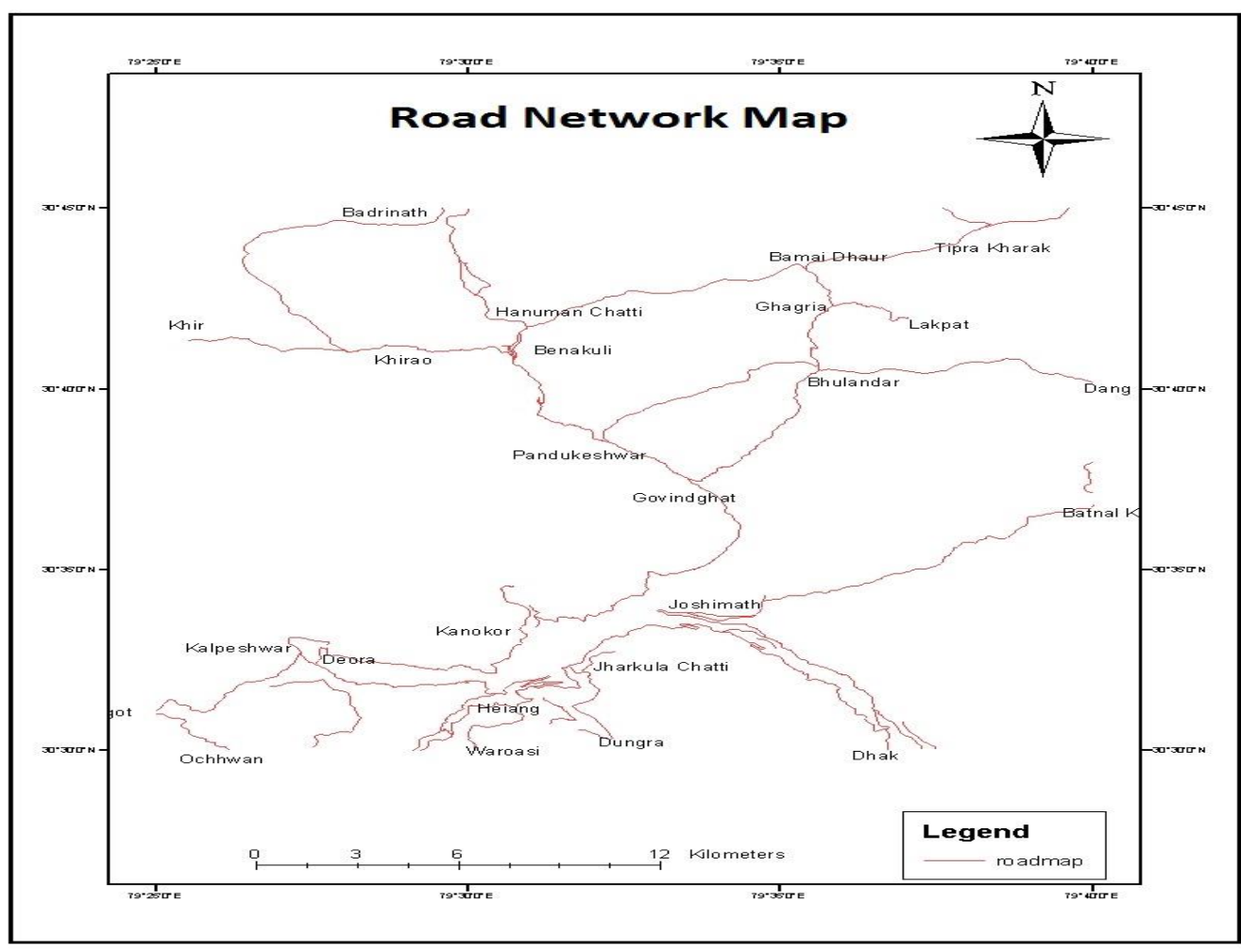

Figure-4: Shows the Network map of study area 


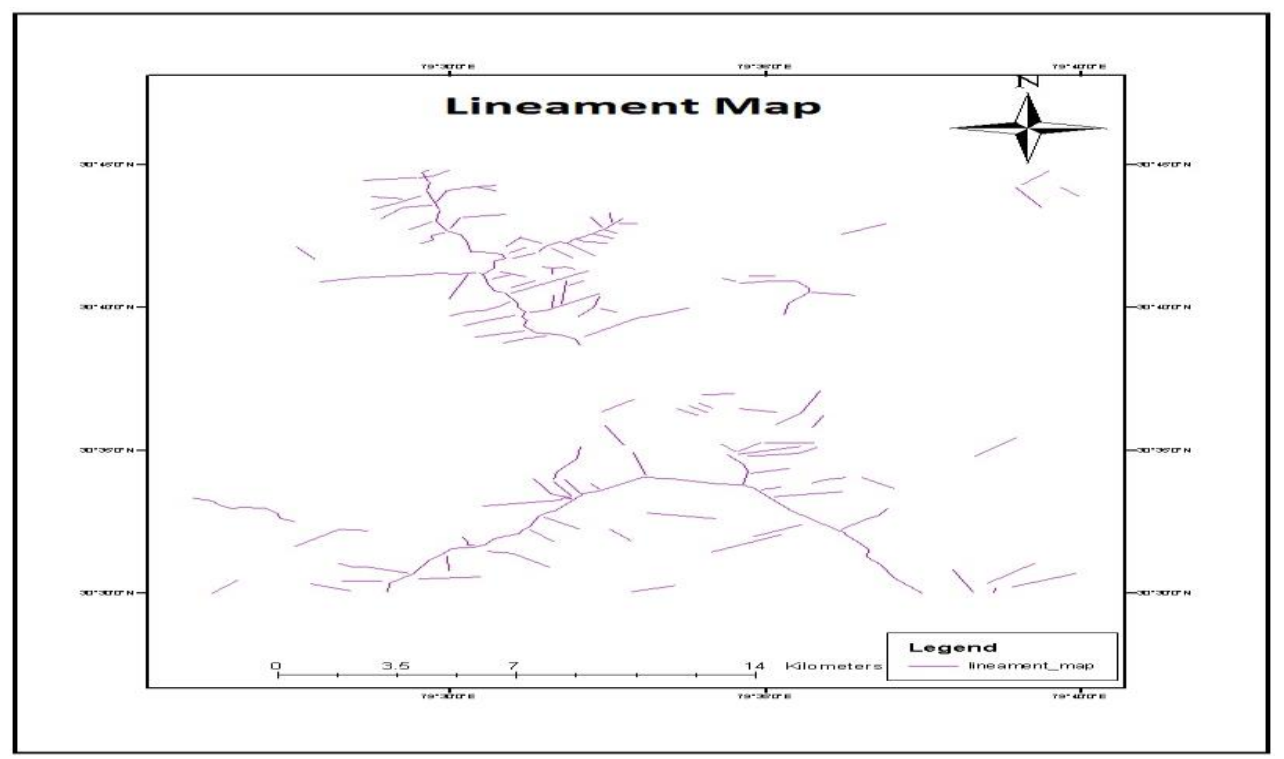

Figure-5: shows the Lineament of study area

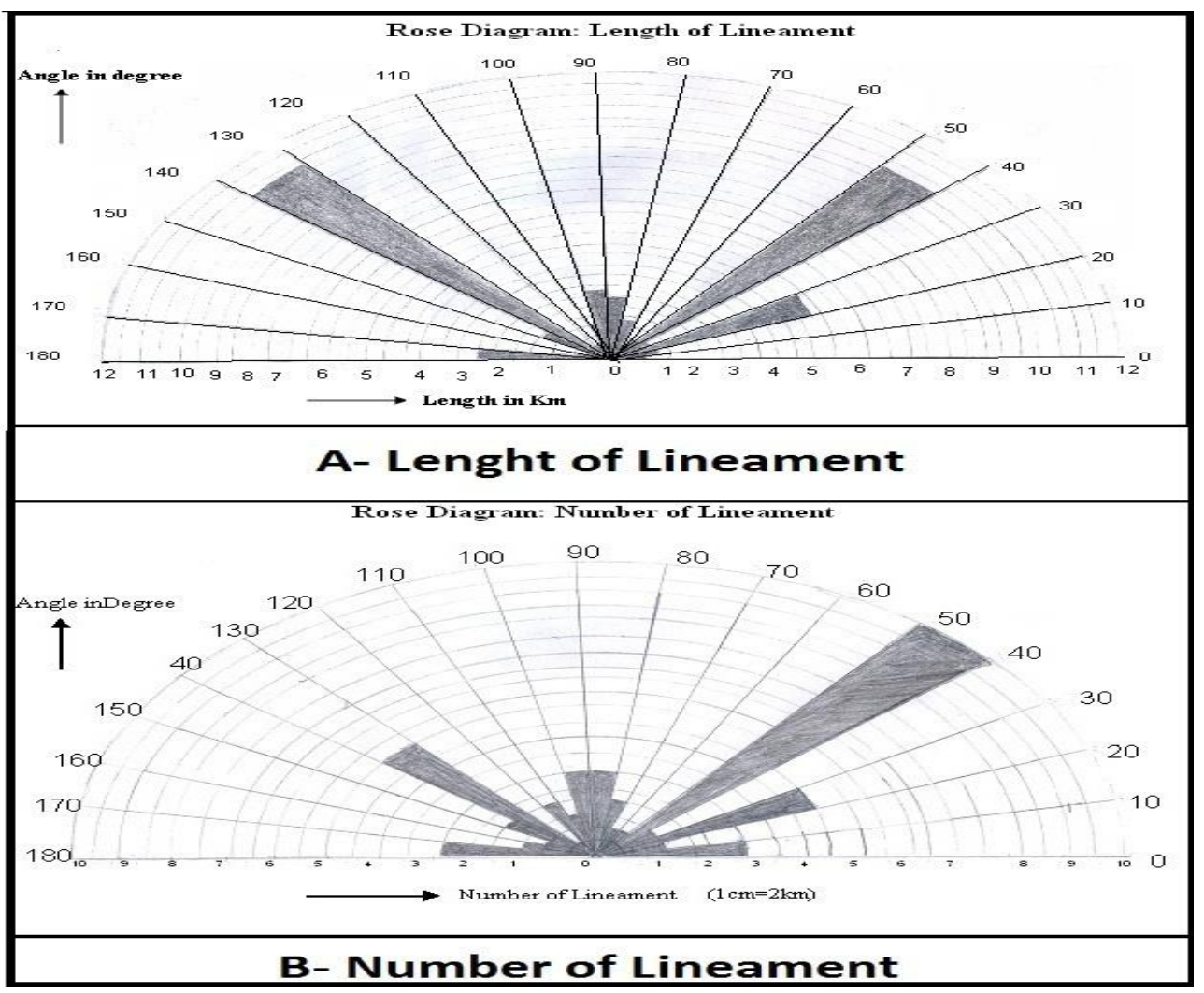

Figure-6: Shows the two category of rose diagram 


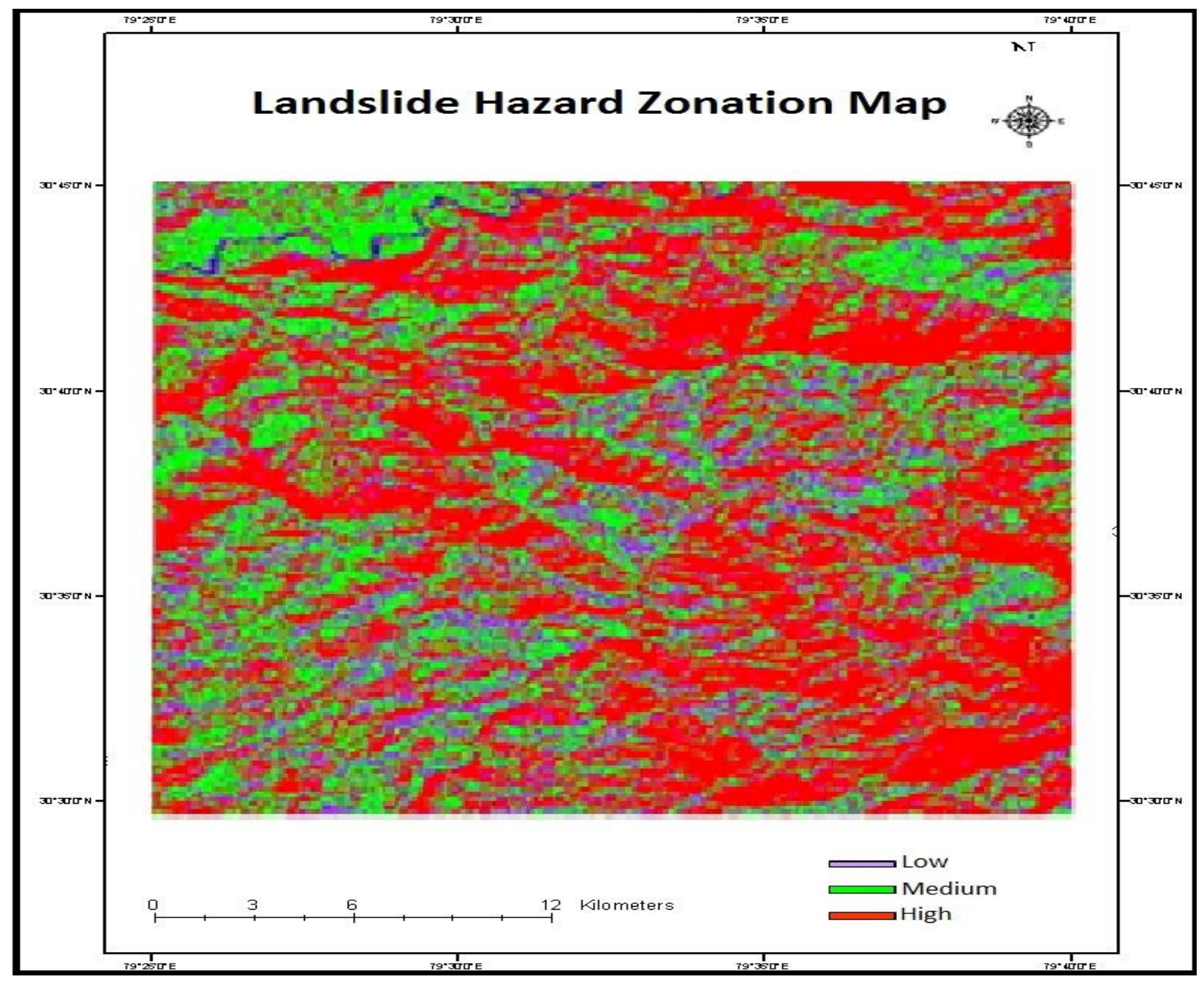

Figure-7: Shows the Landslide Hazard Zonation Map of study area 